\title{
Drugs of Abuse and Metabolites in Urban Wastewater: A Case Study, Rio De Janeiro Municipality, Brazil
}

\author{
Aldo Pacheco Ferreira
}

\begin{abstract}
The use of drugs of abuse is a concern for social and public health aspects, but also for environmental contamination. However, the study of these pollutants becomes important since the magnitude, nature and consumption patterns can be evaluated through the range of compounds detected in wastewater treatment plant (WWTP). Wastewater-based epidemiology depend on the principle that traces of compounds, which a population is exposed to or consume, are excreted unchanged or as metabolites in urine and/or faeces, and at last end up in the sewer network. Quantifying target metabolic residues in raw urban wastewater permits identifying the exposure or use of substances of interest in a community. For this purpose, it was used an HPLC-MS/MS analytical method to assess the concentrations of 2 drug of abuses and metabolites (cocaine and cannabis) in influent samples from Penha WWTP and Ilha do Governador WWTP, in Rio de Janeiro Municipality. A systematic use of cocaine and cannabis was identified by detection in all samples analyzed. This study corroborates with other findings related to the methodological approach which largely can be applied to monitor the use of drug of abuses, giving important subsidies to both environmental and health control systems.
\end{abstract}

Index Terms - Drug of abuse, Wastewater-Based Epidemiology, Environmental Detection, Public Health.

\section{INTRODUCTION}

There are some hypotheses regarding the etiology of the word drug. One is that it may have originated from the Arabic word drowa, which means wheat candy, or else from the Dutch term drooge vate, associated with dry leaves, since the medicines were made from the vegetables. In French it is that the term known today is described as drogue, to designate medicine or pharmaceutical product. Currently, the term drug is associated with substances that change the user's behavioural aspects, giving him pleasure sensations, and is defined by the World Health Organization (WHO) as "any substance not produced by the body that has the property of acting on one or more of its systems, producing changes in its functioning" [1].

Drugs of abuse go into the sewage system, unchanged or as metabolites, most commonly after their consumption and excretion and after illegal discharges as result of police interventions [2]. Data on the occurrence of these compounds in influent waters from wastewater treatment plant (WWTP) provide valuable information on drug use and consumption tendencies at local level [2]-[3]-[4]-[5].

Aldo Pacheco Ferreira, Department of Human Rights and Health, Sergio Arouca National School of Public Health, Oswaldo Cruz Foundation, Rio de Janeiro, Brazil
With the increase of drug consumption in recent decades, in particular cocaine and cannabis, the social impact on society has also propagated [6]. These consequences include rising healthcare costs, crime rates, and economic losses. Therefore, it is imperative that policy makers gain knowledge of the trends, usage levels, hot spots, and overall prevalence of drug of abuse consumption, in order to develop proper prevention campaigns and effective intervention strategies.

Estimation of drug use at the population level is traditionally performed mainly via socio-epidemiological methods, such as population surveys and seizure data. These data are subject to significant uncertainties in measurement and selection, for example, self-reporting bias from false reports, unaware or misinformed consumers, and limited population coverage of the study [7]-[8].

Drug of abuse consumption is actually an important public health concern that needs to be well defined to be managed. A new concept to assess collective drug consumption, based on measuring concentrations of drug of abuses and their excreted human metabolites in untreated sewage, was proposed by Daughton [9] and developed by Zuccato et al. [10]. The technique is based on the principle that excreted drug residuals in the sewage can be collected by the downstream end of urban drainage systems and subsequently analysed. Later, this approach, termed wastewater-based epidemiology (WBE). Levels of drug of abuses (parent compounds or metabolites) in wastewater can be used to back-calculate the total consumption of drug of abuse by the population served by a particular WWTP.

Sampling campaigns for the purpose of detection of excreted drug residuals (drug biomarkers) are usually performed at the inlet to WWTPs. There have been many studies to monitor temporal and spatial patterns of drug use in selected urban sewer catchments [11]-[12]-[13] allowing, more recently, for the undertaking of international comparative studies [2]-[14]. These findings demonstrated that wastewater analysis techniques have the potential to complement conventional surveillance data. Estimation of drug use via wastewater analysis has been further expanded to include monitoring during special events (e.g. music festivals) [15]-[16], as well as within smaller communities (e.g. prisons) [17]-[18]. Despite the claim for protection of anonymity and non-intrusive approaches, various ethical concerns and debates have been raised with regards to the privacy of individuals and how far upstream one can perform monitoring in this way [19].

Drug of abuse are recognised as environmental pollutants of 
emerging concern to both human and ecological health, whose impact on ecosystems is still poorly understood [20]. There has been a growing interest in the study of these substances due to their high consumption and continuous discharge in environmental compartments, after their insufficient elimination in WWTPs. The nature and quantity of these pollutants are frequently related to the characteristics, state of health and habits of the populations that discharge these WWTPs. Therefore, the study of these pollutants has a double aspect: epidemiologically the magnitude, nature and consumption patterns can be evaluated through the range of compounds detected in the WWTPs, environmentally trace, and manage the danger that these substances can be traced represent for human and environmental health [4].

Regarding the relationship of drugs to health, the World Drug Report 2017 [21] aims to present data and strategies to analyze social issues of marginalization, gender, incarceration, confrontation and combat the world drug problem with prevention and treatment policies, punishments and alternative measures, among others, embracing the goals of the 2030 Sustainable Development Agenda " [22].

It is detached by Campos [23] that in Brazil, in particular in Rio de Janeiro, people living in a slums conjuncture live in a scenario where crime, impunity and social injustice are prevalent, fuelled by expressions of uprooting and vulnerability facing the violence of the State, militias or trafficking.

The increasing use of drugs of abuse and the non-medical use of prescription drugs are a growing concern for public health authorities [24]. According to the data provided by population surveys, around 255 million people worldwide, which is approximately 5.6 percent of the world population aged 15 to 64 years, used drugs at least once during 2016 [21]. Around 31 million people who use drugs of abuse suffer from their disorders, which mean that their use of drugs is harmful to the point where they may need treatment. According to the same report, cannabis users (Cannabis sativa L.) comprise the largest number of users. Figure 1 presents the global trends in estimated number of drug users and disorders derived from their use in the period of 2006-2015 [21].

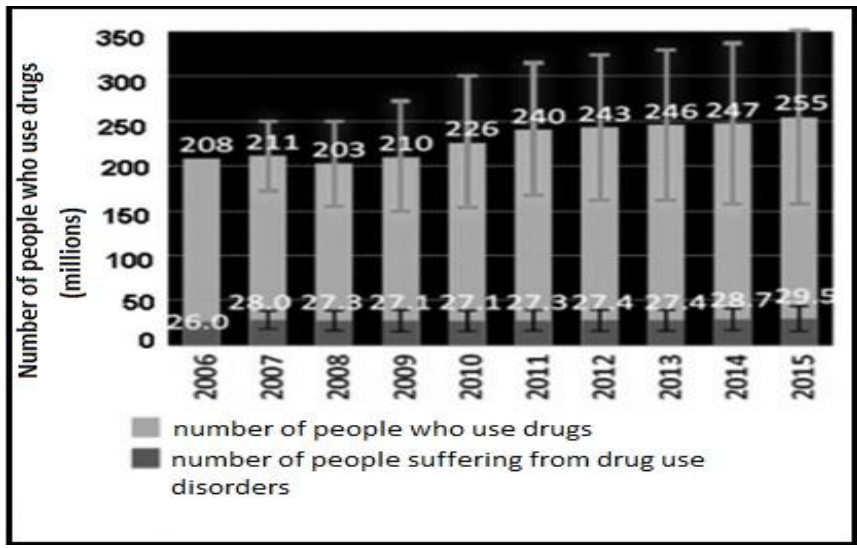

Fig 1. Global trends in estimated number of drug users and disorders arising from their use in the period 2006-2015 [21]

The aim of the present work was to study the occurrence and distribution of drugs of abuse (cocaine and cannabis), in the influent from WWTP Penha and WWTP Ilha do Governador,
Rio de Janeiro Municipality, Rio de Janeiro State, Brazil (Figure 2). These areas are affected by different anthropogenic pressures, including wastewater release, industrial effluents, and municipal activities. For these purposes, a highly sensitive analytical method was developed and validated for the determination of the main drugs of abuse and their metabolites in WWTPs.
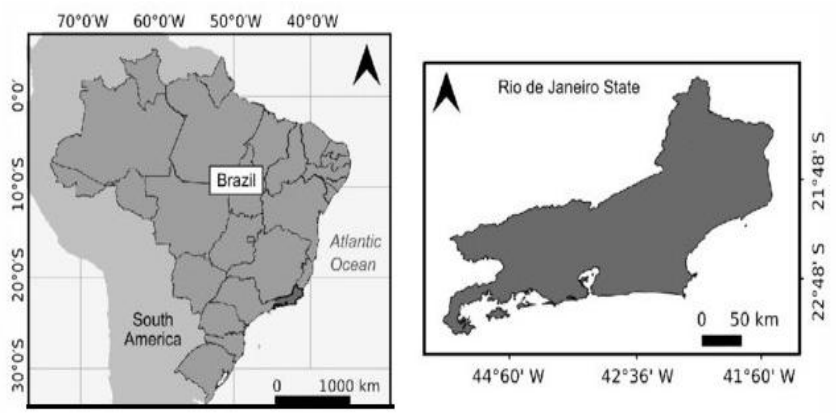

Fig 2. Location of Rio de Janeiro municipality, Rio de Janeiro state, Brazil

\section{MATERIALS AND METHODS}

\section{A. Characterizing the WWTP}

It is noteworthy that the wastewater samples collected comes from catchment areas where several schools, universities, hospitals, business offices, shops, entertainment venues and clubs are located, and in a minor extent some industries.

\section{B. WWTP Penha}

The WWTP Penha $\left(22^{\circ} 49^{\prime} 57^{\prime \prime S} \quad 43^{\circ} 16^{\prime} 0^{\prime \prime} \mathrm{W}\right)$ operates with biofilters and activated sludge, treating a flow of $1600 \mathrm{~L} / \mathrm{s}$. The pre-treatment starts by medium and fine screening, with removal of solids, followed by removal of sands, oils, and grease. Greases are incinerated. The primary treatment consists of an accelerated lamellar settling in four tanks, with optional physical and chemical treatment, and of three tanks of equalization/homogenization. The secondary biological treatment is performed by means of a continuous-flow activated sludge system with conventional aeration in six aerated tanks by surface aeration, followed by a secondary lamellar settling, in 12 settlers of rectangular plant, with biological sludge recirculation.

\section{WWTP Ilha do Governador}

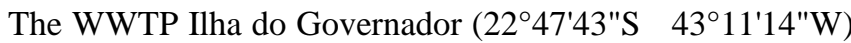
operates with activated sludge, treating a flow of $525 \mathrm{~L} / \mathrm{s}$. The treatment process works with the steps: the elevated influent pass through a screening formed by grids - a coarse and a medium, responsible for removing coarse solids, followed by the removal of oils, greases and sands, in two grit chambers/degreasers. The resulting by-products of this pre-treatment are later deposited in controlled landfill. The influent is then fed to a homogenization tank e with $4000 \mathrm{~m} 3$ working volume, whose function is to regularize peaks of pollutant load. The subsequent primary treatment consists of a preliminary step of physical and chemical treatment, with application of aluminium sulphate, hydrated lime and a polyelectrolyte on two lines of coagulation/flocculation tanks, with primary settling in two tanks of circular plant with 
bottom and surface scraper. The primary effluent is then fed to the secondary treatment, which is performed by means of activated sludge system, in six aeration tanks provided of two surface aerators each and sludge recirculation tank. The next step is the secondary settling in two settlers of circular plant, with bottom and surface scraper.

\section{Chemicals and materials}

Standard solutions of cocaine (COC), benzoylecgonine (BZE), norcocaine (NOR), ecgonine methyl ester (EME), cocaethylene (CET), 11-nor-delta-9hydroxytetrahydrocannabinol (THC-COOH), cocaine- $\mathrm{d}_{3}$, BZE- $\mathrm{d}_{3}$, EME- $\mathrm{d}_{3}$, CET- $\mathrm{d}_{8}$, THC-COOH-d $\mathrm{d}_{3}$, in methanol $(\mathrm{MeOH})$ or acetonitrile $(\mathrm{ACN})$, were purchased from LGC Standards (S.J. dos Campos, SP, Brazil).

$\mathrm{MeOH}$ and ACN, HPLC grade (Hipersolv Chromanorm), formic acid (FA) (Normapur) and ammonium formate (AF) (Normapur) were purchased from VWR (Bela Aliança, São Paulo- SP, Brazil). Ultra-pure water was produced using successive Milli-RO reverse-osmosis filtration and the Milli-Q Plus water purification system (Merck Millipore, Rio de Janeiro, Brazil).

Solid Phase Extraction (SPE) cartridges Oasis HLB (500 $\mathrm{mg} / 6 \mathrm{~mL}$ ) and Xbridge Phenyl $3.5 \mathrm{~mm}, 3 \mathrm{~mm} \times 150 \mathrm{~mm}$ HPLC column were purchased from Waters (Guyancourt, France).

Analysis was carried out with a Thermo Accela pump and Accela sampler coupled to a triple quadrupole mass spectrometer Quantum Access Max equipped with Xcalibur software (ThermoFisher Scientific, Jundiaí, São Paulo, Brazil).

\section{E. Sample collection}

The 24-h composite influent wastewater samples were collected daily over five consecutive days in 2018, starting on Monday September 10th and ending on Friday September 14th. Sampling was carried out using cooling auto samplers to obtain 24-h flow-weighted composite influent samples with a sampling frequency of at least 6 times per hour according to the local WWTP procedures. At the end of sampling, 2 L samples were collected in polypropylene bottles and sent to laboratory in a cool box intended to be used for 24-h shipments. Upon receipt, samples were filtered and extracted according to the following protocol and the extracts were stored at $4^{\circ} \mathrm{C}$ before analysis.

\section{F. Target analytes}

The following compounds were analyzed: The cocaine group that contains COC and its metabolites, BZE, EME, CET and norcocaine (NOR), and the cannabinoid THC-COOH.

\section{G.Analytical Methods}

\section{Solid-phase extraction (SPE)}

Samples were filtered on glass fiber filters $(1 \mathrm{~mm}, \mathrm{GF} / \mathrm{B}$ Whatman) before SPE extraction. Isotopically labeled compounds were added to $250 \mathrm{~mL}$ of WWTP influent. Cartridges were conditioned by following elution of $2 \times 5 \mathrm{~mL}$ $\mathrm{MeOH}$ and $2 \times 5 \mathrm{~mL}$ ultra-pure water. Samples were percolated at a flow rate of $2 \mathrm{~mL} / \mathrm{min}$. The SPE cartridges were then washed using $2 \times 5 \mathrm{~mL}$ ultra-pure water and dried for $30 \mathrm{~min}$. Analytes were eluted with $2 \times 5 \mathrm{~mL}$ of $\mathrm{MeOH}$ and eluates were evaporated to dryness under a gentle stream of nitrogen. Extracts were reconstituted in $500 \mathrm{~mL}$ of $\mathrm{MeOH}$ and kept frozen until analysis. A $5 \mu \mathrm{L}$ volume was injected for HPLC-MS/MS analysis.

The complete run time of $26 \mathrm{~min}$, with analytes eluting between 0.8 and $19 \mathrm{~min}$, provided effective analysis time. Average mass accuracy for all target drugs of abuse was below $5 \mathrm{ppm}$ and the standard deviation of these errors was from 0.1 to 0.9 , which point to a very low deviation of the instrument response. Purity score values higher than $82.4 \%$ were at all times obtained in HPLC-MS/MS identification. In sewage, recoveries ranged from $61 \%$ for THC-COOH to $119 \%$ for BZE. Because of the loss during SPE extraction and the matrix effect, the efficiency values ranged from $24 \%$ to $57 \%$ in influents. Linearity was confirmed for all of the compounds in their relative concentration range using the IS (Internal Standard) addition method with correlation coefficient $r$ values above 0.99 (Table 1).

Data analysis (counts, percentages, and means) were performed with Excel software (Microsoft Office Excel 2016 for Apple ${ }^{\mathrm{TM}}$ ). The level of significance was calculated by two sample $t$ test with unequal variance performed with the STATA MP statistical software package v14.1 for Apple ${ }^{\text {TM }}$ (Stata Corp).

Table 1. Analytical validation data

\begin{tabular}{lccccc}
\hline Molecules & $\begin{array}{c}\text { Recovery } \\
(\%)\end{array}$ & $\begin{array}{c}\text { Ef?ciency } \\
(\mathbf{\%})\end{array}$ & $\begin{array}{c}\text { Linearity } \\
(\mathbf{4 0 0} \mathbf{n g} / \mathrm{L})\end{array}$ & $\begin{array}{c}\text { Intra-run } \\
\text { precision } \\
(\mathbf{4 0 0} \mathbf{n g} / \mathrm{L})\end{array}$ & $\begin{array}{c}\text { LOQ } \\
(\mathbf{n g})\end{array}$ \\
\hline COC & 107 & 36 & 0.999 & 2.42 & 20 \\
BZE & 119 & 54 & 1.000 & 0.52 & 10 \\
EME & 110 & 24 & 0.997 & 3.58 & 40 \\
NOR & 105 & 34 & 0.994 & 2.35 & 20 \\
CET & 109 & 41 & 0.999 & 4.02 & 5 \\
THC-COOH & 61 & 57 & 0.998 & 14.41 & 5 \\
\hline
\end{tabular}

Intra-run precision: three time analyses of a $400 \mathrm{ng} / \mathrm{L}$ spiked wastewater sample; Linearity range: $12.5,25,50,100$, and 200 $\mu \mathrm{g} / \mathrm{L}$; LOQ - limits of quantification. 


\section{RESUlTS AND DisCUSSION}

Concentrations measured in influent wastewater samples from WWTP Penha and WWTP Ilha do Governador are summarized in Table 2 and Table 3.

Table 2. Concentrations (ng/L) of drug of abuses detected in replicate samples from the WWTP - Penha, Rio de Janeiro, 2018

\begin{tabular}{cccccccc}
\hline \multirow{2}{*}{$\begin{array}{c}\text { Compound } \\
\text { analy sed }\end{array}$} & $\begin{array}{c}\text { Sample } \\
\text { collection }\end{array}$ & Mean & SD & $\begin{array}{c}\text { Low er 95\% CI } \\
\text { of Mean }\end{array}$ & $\begin{array}{c}\text { Upper 95\% CI } \\
\text { of Mean }\end{array}$ & LI & LM \\
\cline { 3 - 8 } & $1^{\text {th }}$ & 102.2 & 14.83709 & 99.19 & 105.2 & 67 & 198 \\
COC & $2^{\text {nd }}$ & 111.8 & 8.99663 & 109.98 & 113.62 & 90 & 156 \\
& $3^{\text {rd }}$ & 120.4 & 11.60171 & 118.05 & 122.75 & 54 & 167 \\
& $4^{\text {th }}$ & 101.5 & 14.31378 & 98.6 & 104.4 & 53 & 162 \\
\hline \multirow{3}{*}{ BZE } & $1^{\text {th }}$ & 242.7 & 18.83732 & 238.88 & 246.51 & 167 & 293 \\
& $2^{\text {nd }}$ & 247.9 & 40.87297 & 239.61 & 256.18 & 133 & 369 \\
& $3^{\text {rd }}$ & 288.8 & 21.39042 & 284.47 & 293.14 & 189 & 344 \\
& $4^{\text {th }}$ & 211.6 & 22.62252 & 207.02 & 216.19 & 112 & 282 \\
\hline \multirow{2}{*}{ THC-COOH } & $1^{\text {th }}$ & 39.6 & 6.64669 & 38.26 & 40.95 & 26 & 89 \\
& $2^{\text {nd }}$ & 42.8 & 5.89669 & 41.61 & 44 & 16 & 86 \\
& $3^{\text {rd }}$ & 38.2 & 4.53204 & 37.28 & 39.12 & 15 & 67 \\
& $4^{\text {th }}$ & 44.9 & 4.8286 & 43.92 & 45.87 & 19 & 74 \\
\hline
\end{tabular}

SD - Standard Deviation; CI - confidence interval; LI - limit inferior; LS - limit superior

It was found in all influent samples. COC and its metabolite BZE showed concentration values in both WWTP. The mean values of COC exceeded $100 \mathrm{ng} / \mathrm{L}$ in all analysis, BZE exceeded $200 \mathrm{ng} / \mathrm{L}$ in all samples from WWTP Penha and $300 \mathrm{ng} / \mathrm{L}$ in all samples from WWTP Ilha do Governador. THC-COOH was found in all samples at average concentration of 38.2 and 44.9 ng/L for WWTP Penha and 39.7 and 65.4 for WWTP Ilha do Governador, respectively. These concentrations are very similar to the range of compounds detected in untreated wastewater from WWTPs in Colombia and in Europe. On the other hand, the values found for COC and BZE are significantly lower than those found in another Brazilian study. COC levels ranged from $519 \pm 29$ to $1260 \pm 79 \mathrm{ng} / \mathrm{L}$ whereas for BZE, its major metabolite concentration varied between $1228 \pm 98$ and $4297 \pm 298$ $\mathrm{ng} / \mathrm{L}[25]$.

Table 3. Concentrations (ng/L) of drug of abuses detected in replicate samples from the WWTP - Ilha do Governador, Rio de Janeiro, 2018

\begin{tabular}{cccccccc}
\hline \multirow{2}{*}{$\begin{array}{c}\text { Compound } \\
\text { analysed }\end{array}$} & $\begin{array}{c}\text { Sample } \\
\text { collection }\end{array}$ & Mean & SD & $\begin{array}{c}\text { Low er 95\% CI } \\
\text { of Mean }\end{array}$ & $\begin{array}{c}\text { Upper 95\% CI } \\
\text { of Mean }\end{array}$ & LI & L M \\
\cline { 3 - 8 } & $1^{\text {th }}$ & 143.4 & 8.52177 & 141.67 & 145.12 & 112 & 198 \\
COC & $2^{\text {nd }}$ & 141.6 & 13.61692 & 138.85 & 144.36 & 98 & 199 \\
& $3^{\text {rd }}$ & 192.6 & 34.08487 & 185.70 & 199.51 & 102 & 288 \\
& $4^{\text {th }}$ & 155.4 & 20.39633 & 151.26 & 159.53 & 83 & 211 \\
\hline \multirow{2}{*}{ BZE } & $1^{\text {th }}$ & 396.3 & 55.37131 & 385.08 & 407.52 & 299 & 543 \\
& $2^{\text {nd }}$ & 399.5 & 50.16016 & 389.34 & 409.66 & 302 & 555 \\
& $3^{\text {rd }}$ & 381.1 & 63.60296 & 368.22 & 393.99 & 278 & 555 \\
& $4^{\text {th }}$ & 403.7 & 41.35421 & 395.32 & 412.08 & 299 & 516 \\
\hline \multirow{2}{*}{ THC-COOH } & $1^{\text {th }}$ & 57.3 & 10.13916 & 55.25 & 59.36 & 31 & 86 \\
& $2^{\text {nd }}$ & 65.4 & 7.94253 & 63.79 & 67.01 & 39 & 92 \\
& $3^{\text {rd }}$ & 45.1 & 5.99382 & 43.89 & 46.32 & 33 & 73 \\
& $4^{\text {th }}$ & 39.7 & 4.65916 & 38.75 & 40.64 & 26 & 51 \\
\hline
\end{tabular}

SD - Standard Deviation; CI - confidence interval; LI - limit inferior; LS - limit superior and receiving surface waters due to incomplete removal of A number of drug of abuses have so far been detected in raw these drugs by conventional WWTP processes [4]. Even after municipal wastewater as well as treated wastewater effluent the prevalence of illicit substances/metabolites in different 
water sources was established and in light of growing concern about their unknown effects, very few studies have reported on their degradation behaviour and eco-toxicological impacts, with most studies based on detection/analysis, or usage patterns/trends. There are largely unknown natures of the ecological effects from these substances, stating that while the half-life of some drug of abuses is short, they become more prevalent with continued population usage and environmental release and as such, they cannot be ignored. Therefore, these substances are considered ubiquitous contaminants that are continuously discharged from WWTPs into the receiving environment, but with essentially unknown effects on human and environmental health from chronic low-level exposure.

Due to the complexity involved in the issue, it is important to analyze the use of drugs, as well as their effects and derived political practices, based on the articulation and mediation of factors of an individual, sociocultural and political-economic nature. Therefore, by virtue of the consequences of use in the lives of individuals and communities, as well as prevailing prejudices and stigmas, the inclusion of this topic in the public policy agenda is accompanied, with the health sector having a prominent role [26].

Consumption of drug of abuses is a new concern for water management that must be considered not only because of the social and public health aspects but also in an environmental context in relation with the contamination of surface waters. Indeed, WWTP effluents contain drug residues that have not been eliminated since WWTP treatments are not completely efficient in their removal.

It should be noted that the violence resulting from the illicit drug market has a direct impact on the quality of life of people, affecting health, even though this does not result directly from the actions related to prevention or health care. The daily stress of people who live or need to go through locations dominated by violent criminal factions strongly affects public health and can result in diseases of various shades, some of which are only detectable in a relevant time course. Peace of mind itself is a dimension of the quality of life that public health needs to be aware of. It is not correct, therefore, to simplify the ills to public health that result to the figure of the user.

\section{CONCLUSION}

The increasing use of drug of abuses and the nonmedical use of prescription medications are a growing concern for public health authorities. In consequence, environmental existence of chemical pollutants through negligenciated interconnectedness of human actions and activities influence the environment in countless ways. These impacts ascending from specially deposition of drug of abuses harbours underestimated risks to ecosystem and the lives, which live there. The individual use of these pharmacologically active substances generates great but underappreciated levels of other toxicologically potent and associated bioactive metabolites through purposeful and inadvertent discharge to the environment via excreta and by illegal disposal. These facts have important in many environmental health aspects as well as on population health.
The length of time that drug of abuses remain in the health system varies widely depending on the extent of the local sewage collection network. The biological nature, temperature and composition of the sanitary tributary present high variation among different regions, due to rainfall precipitation, consumption culture, climate, among other factors. Due to such variations, the degradation of drug of abuses should be considered in the estimation of consumption. For the estimation of cocaine use through the epidemiology of the sewage, $10 \%$ uncertainty is assumed in the determination of BE concentration, due to the stability of COC and BZE.

The results, although preliminary are innovative in the study region, being extremely significant, and of concern from an environmental and public health point of view. It proves the relevance of the sewage epidemiology method that should be considered as an efficient tool to support harm-reduction activities and prevention policy. This study could be the reason for the launching of a large-scale study with repeated campaigns, intended for risk reduction management and health purpose.

For wastewater-based epidemiology to produce reliable estimates of drug of abuse use and to inform the development of novel applications, the most urgent future research needs are to improve the methodology by checking and reducing uncertainty factors for each single step; to improve the comparability of results produced by different researchers or studies by adopting a common protocol of action, which will include ethical standards; and to develop methods to integrate wastewater analysis with established methods of drug epidemiology.

In conclusion, research on the presence of drug of abuses, particularly as active compounds in the environment, are vital to improve knowledge of the types consumed, its occurrence, being able to unfold to analyse the exposure and the impact of these compounds in the environment, giving, also, important subsidies for the health management.

\section{ACKNOWLEDGMENT}

The study was funded by the National Council for Scientific and Technological Development (CNPq). Thanking Cedae for its collaboration in obtaining samples and Fiocruz Laboratories.

\section{REFERENCES}

[1] WHO (World Health Organization). The rational use of drugs: report of the conference of experts. Available at: http://www.who.int/iris/handle/10665/37174

[2] K.V. Thomas, L. Bijlsma, S. Castiglioni, A. Covaci, E. Emke, R. Grabic, F. Hernández, S. Karolak, B. Kasprzyk-Hordern, R.H. Lindberg, M. Lopez de Alda, A. Meierjohann, C. Ort, Y. Pico, J.B Quintana, M. Reid, J. Rieckermann, S. Terzic, A.L.N. van Nuijs, P. de Voogt. Comparing illicit drug use in 19 European cities through sewage analysis. Sci. Total Environ., 432, (2012) 432-439.

[3] E. Zuccato, C. Chiabrando, S. Castiglioni, R. Bagnati, R. Fanelli. Estimating community drug abuse by wastewater analysis. Environ Health Perspect., 116, (2008) 1027-32.

[4] A.L.N. van Nuijs, J-F. Mougel, I. Tarcomnicu, L. Bervoets, R. Blust, P.G. Jorens, H. Neels, A. Covaci. Sewage epidemiology - a real-time approach to estimate the consumption of illicit drugs in Brussels, Belgium. Environ Int., 37, (2011) 612-621.

[5] T. Nefau, S. Karolak, L. Castillo, V. Boireau, Y. Levi. Presence of illicit drugs and metabolites in influents and effluents of 25 sewage 
water treatment plants and map of drug consumption in France. 2013. Sci Total Environ., 461-462, (2013) 712-22.

[6] European Monitoring Centre for Drugs and Drug Addiction EMCDDA. European Drug Report 2015. Available at http://www.emcdda.europa.eu/edr2015

[7] C. Banta-Green, J. Field. Citywide drug testing using municipal wastewater. Significance, 8, (2011) 70-74.

[8] S. Castiglioni, K.V. Thomas, B. Kasprzyk-Hordern, L. Vandam, P. Griffiths. Testing wastewater to detect illicit drugs: State of the art, potential and research needs. Sci. Total Environ., 487, (2014) 613-620.

[9] C.G. Daughton. Illicit drugs in municipal sewage: proposed new non-intrusive tool to heighten public awareness of societal use of illicit/abused drugs and their potential for ecological consequences. In: American Chemical Society, Symposium Series. American Chemical Society, Symposium Series, Washington, DC, (2001) 348-364.

[10] E. Zuccato, C. Chiabrando, S. Castiglioni, D. Calamari, R. Bagnati, S. Schiarea, R. Fanelli. Cocaine in surface waters: a new evidence-based tool to monitor community drug abuse. Environmental Health: A Global Access Science Source, 4, (2005) 1-7.

[11] R.L. Gomes, M.D. Scrimshaw, J.N. Lester. Fate of conjugated natural and synthetic steroid estrogens in crude sewage and activated sludge batch studies. Environ. Sci. Technol., 43, (2009) 3612-3618.

[12] S. Castiglioni, L. Bijlsma, A. Covaci, E. Emke, F. Hernández, M. Reid, C. Ort, K.V. Thomas, A.L.N. van Nuijs, P. De Voogt, E. Zuccato. Evaluation of uncertainties associated with the determination of community drug use through the measurement of sewage drug biomarkers. Environ. Sci. Technol., 47, (2013) 1452-1460.

[13] B.G. Plósz, M.J. Reid, M. Borup, K.H. Langford, K.V. Thomas. Biotransformation kinetics and sorption of cocaine and its metabolites and the factors influencing their estimation in wastewater. Water Res., 47, (2013) 2129-2140.

[14] C. Ort, A.L.N van Nuijs, J.D. Berset, L. Bijlsma, S. Castiglioni, A. Covaci, P. de Voogt, E. Emke, D. Fatta-Kassinos, P. Griffiths, F. Hernández, I. González-Mariño, R. Grabic, B. Kasprzyk-Hordern, N. Mastroianni, A. Meierjohann, T. Nefau, M. Östman, Y. Pico, I. Racamonde, M. Reid, J. Slobodnik, S. Terzic, N. Thomaidis, K.V. Thomas. Spatial differences and temporal changes in illicit drug use in Europe quantified by wastewater analysis. Addiction, 109, (2014) 1338-1352.

[15] D. Gerrity, R.A. Trenholm, S.A. Snyder. Temporal variability of pharmaceuticals and illicit drugs in wastewater and the effects of a major sporting event. Water Res., 45, (2011) 5399-5411.

[16] F.Y. Lai, P.K. Thai, J.O. Brien, C. Gartner, R. Bruno, B. Kele, C. Ort, J. Prichard, P. Kirkbride, W. Hall, S. Carter, J.F. Mueller. Using quantitative wastewater analysis to measure daily usage of conventional and emerging illicit drugs at an annual music festival. Drug Alcohol Rev., 32, (2013) 594-602.

[17] H.F. Schröder, W. Gebhardt, M. Thevis. Anabolic, doping, and lifestyle drugs, and selected metabolites in wastewater-detection, quantification, and behaviour monitored by high-resolution MS and MSn before and after sewage treatment. Anal Bioanal Chem., 398, (2010) 1207-1229.

[18] C. Postigo, M.L. Alda, D. Barceló. Evaluation of drugs of abuse use and trends in a prison through wastewater analysis. Environ. Int., 37, (2011) 49-55.

[19] W. Hall, J. Prichard, P. Kirkbride, R. Bruno, C. Gartner, C. Ort, J.F. Mueller. An analysis of ethical issues in using wastewater. Addiction, 107, (2012) 1767-1773.

[20] M.K. Yadav, M.D. Short, R. Aryal, C. Gerber, B. van den Akker, C.P. Saint. Occurrence of illicit drugs in water and wastewater, and their removal during wastewater treatment. Water Research, S0043-1354, 17, (2017) 30641-30643.

[21] UNODC (United Nations Office on drugs and crime). World Drug Report 2017. United Nations publication, Sales No. E.16.XI.7, 2017.

[22] UNODC (United Nations Office on drugs and crime). World Drug Report 2016. United Nations publication, Sales No. E.16.XI.7, 2016.

[23] [23] R.R. Campos. Geografia política das drogas ilegais. Leme: JHMizuno, 2014.

[24] OPS (Organización Panamericana de la Salud). Observatorio Internacional de Capacidades Humanas, Desarrollo y Políticas Públicas.

Available http://capacidadeshumanas.org/oichsite/wp-content/uploads/2015/07/ OICH_Estudios-y-An--lisis2.pdf

[25] WHO (World Health Organization). Health topics: substance abuse. Available at: https://www.who.int/topics/substance_abuse/en/
[26] H.A. Whiteford, L. Degenhardt, J. Rehm, A.J. Baxter, A.J. Ferrari, H.E. Erskine, F.J. Charlson, R.E. Norman, A.D. Flaxman, N. Johns, R. Burstein, J.L. Christopher, C.J.L. Murray, T. Vos. Global burden of disease attributable to mental and substance use disorders: findings from the Global Burden of Disease Study 2010. The Lancet, 382, 9904, (2013) 1575-1586. 